\title{
A Traumatic Dislocation of the Atlas from the Axis in a Patient with Atlantooccipital Assimilation
}

\author{
Raja Gnanadev ${ }^{1}$, Basem Ishak ${ }^{2}$, Joe Iwanaga ${ }^{3}$, Marios Loukas ${ }^{4}$, R. Shane Tubbs ${ }^{2}$ \\ 1. Miscellaneous, Seattle Science Foundation, Seattle, USA 2. Neurosurgery, Seattle Science Foundation, Seattle, USA 3. \\ Medical Education and Simulation, Seattle Science Foundation, Seattle, USA 4. Medical Education and Simulation, St. \\ George's University School of Medicine, St. George, GRD
}

Corresponding author: Joe Iwanaga, iwanagajoeca@gmail.com

\begin{abstract}
Atlantooccipital assimilation is defined as the complete or partial fusion of the caudal portion of the occiput with the cranial portion of the atlas. We report an extremely rare case of a traumatic dislocation of the atlas from the axis ( $\mathrm{C} 1$ from $\mathrm{C} 2$ ), which lead to internal decapitation in a patient with atlantooccipital assimilation. This report reviews the background of atlantooccipital assimilations and their clinical relevance.
\end{abstract}

Categories: Neurosurgery, Other, Trauma

Keywords: trauma, craniocervical, congenital, assimilation

\section{Introduction}

Atlantooccipital (AO) assimilation is defined as the complete or partial fusion of the occiput with the atlas [1]. The prevalence of atlantooccipital assimilation ranges from $0.08 \%-3 \%$ and may be congenital or acquired [2].

The dislocation of the atlantoaxial joint often leads to internal decapitation. The primary mechanism of injury is trauma: dives, falls, assault, and motor vehicle accidents [3]. We report an extremely rare case of traumatic dislocation of the atlas from the axis, leading to internal decapitation in a pediatric patient with $\mathrm{AO}$ assimilation. This report reviews the background and clinical relevance of $\mathrm{AO}$ assimilations.

Received 02/21/2019

Review began 02/23/2019 Review ended 02/24/2019 Published 04/06/2019

() Copyright 2019

Gnanadev et al. This is an open access article distributed under the terms of the Creative Commons Attribution License CC-BY 3.0., which permits unrestricted use, distribution, and reproduction in any medium, provided the original author and source are credited.
A review of the literature was conducted through Google Scholar, PubMed, and Google Books using keywords including, but not limited to, "atlantooccipital assimilation," "atlantooccipital fusion," “atlantoaxial dissociation," “atlantoaxial dislocation,” and "basilar invagination.” This search yielded no literature involving $\mathrm{AO}$ assimilation and a C1-C2 dislocation with internal decapitation.

\section{Case Presentation}

A 16-year-old male presented to the emergency department following a high-speed front-end collision with another vehicle. He was restrained and occupied the front seat of the vehicle that was struck head-on. The speed at the time of the collision was estimated to be in excess of 79 miles per hour. On arrival, the patient was unconscious and not breathing independently. Attempted intubation at the scene was unsuccessful and the patient was pronounced dead soon after arrival to the hospital.

Radiographs at the time of the incident noted internal decapitation with AO assimilation specifically between the anterior arch of the atlas and the basiocciput (Figure 1). No fractures were noted, including the odontoid process. There was no known past medical or surgical history and the AO assimilation was unknown to the family. 


\section{Cureus}

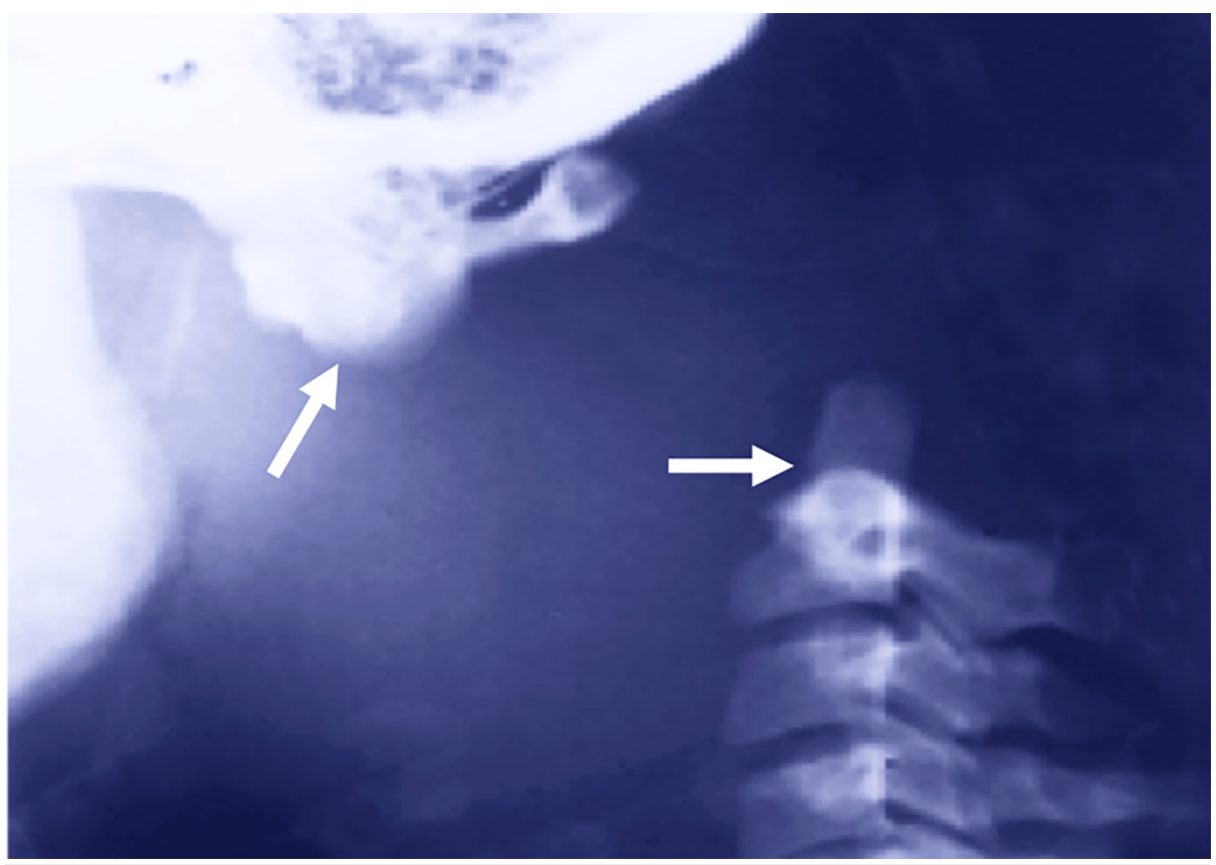

FIGURE 1: Lateral radiograph of the craniocervical junction and upper cervical spine noting that the white arrows point to the assimilated atlas (left) and bare odontoid process of C2 (right)

\section{Discussion}

Two pathologies were observed in the present case: $\mathrm{AO}$ assimilation and complete dislocation of the atlantoaxial joint with an intact odontoid process. AO assimilation is a common anomaly to the upper cervical region $[2,4]$. The prevalence has been cited as $0.08 \%-3.0 \%$ of the population, but more recent studies cite an incidence near 1\% [5-6]. Typically an incidental finding, AO assimilation is due to ponticles from the anterior or posterior arch of the atlas $[2,7]$.

For congenital AO assimilation, the embryology has been described as a failure of differentiation between somites. Specifically, the caudal base of the occiput is derived from the fourth somite and the cranial portion of the atlas from the fifth somite [2]. Abnormalities in the odontoid process, including congenital hypoplasia, have been associated with $\mathrm{AO}$ assimilation $[2,8]$. AO assimilation may be acquired as a result of posttraumatic deformities, infections, inflammatory conditions, or tumors near the craniocervical junction [5-6].

Clinically, the initial visualization of AO assimilation is with X-ray, followed by multiplane, multiecho magnetic resonance imaging (MRI) and computed tomography (CT) with three-dimensional (3D) reconstruction [1]. As mentioned, AO assimilation is typically entirely asymptomatic. The literature describes initial symptoms that are apparent only in the second through fourth decades of life, particularly those related to the regional spinal cord or vascular compression. Symptoms range from transient neck pain and headaches to paresthesias and weakness of the upper extremities [7,1].

The neurological symptoms associated with $\mathrm{AO}$ assimilation are likely related to basilar invagination $[2,8]$. Although it is clear that the two are distinctly related, the literature remains inconsistent with AO assimilation causing basilar invagination or vice versa. Part of this discrepancy may be due to the authors' failure to distinguish basilar invaginations (congenital) from basilar impressions (acquired) $[1,8]$. The neurological symptoms associated with $\mathrm{AO}$ assimilation are considered directly related to the cranial portion of the dens crossing the plane of the foramen magnum, McRae's line [7]. The literature is notable for sudden death in a 24 -year-old patient with $\mathrm{AO}$ assimilation where the foramen magnum had a nearly $50 \%$ reduction in anteroposterior dimensions [9].

AO assimilation and acquired Chiari I malformation have also been reported in the literature [10]. Though the pathophysiologic mechanism is different, both $\mathrm{AO}$ assimilation and Chiari I malformation neurologic symptoms are due to neural tissue compression at the foramen magnum. In a Chiari I malformation, herniating cerebellar tonsils compress neural tissue at the foramen magnum. Both presented with dyspnea and central sleep apnea [11-12].

Trauma as the sole etiology of atlantoaxial dissociations is rare, and in our case, it is associated with a congenital malformation at the atlantooccipital joint. The etiology is often multifactorial, but individual 
causes include congenital relationships and inflammatory etiologies. Congenital associations include Down syndrome, Goldenhar syndrome, and Morquio syndrome. An incidence of $23 \%-83 \%$ of atlantoaxial involvement is also reported in adults with rheumatoid arthritis, predisposing them to atlantoaxial dissociations [4].

Atlantoaxial dislocation is defined as a distance from the atlas' anterior arch to the odontoid process greater than $3 \mathrm{~mm}$ in adults and $5 \mathrm{~mm}$ in children. A distance greater than $7 \mathrm{~mm}$ is likely to require surgical fusion [4]. Internal decapitation, in this case, would likely tear ligaments typically connecting the axis and dens to cranial structures. It is, therefore, important to discuss the regional ligaments and structures expected to be torn.

Along the spinal cord, the posterior longitudinal ligament and the ligamentous articular capsule of the atlantoaxial joints would tear anteriorly, the tectorial membrane posteriorly, and the transverse ligament laterally. The ligaments attaching the dens locally would also tear the apical ligament of the dens, alar ligaments, superior and inferior longitudinal bands of the cruciform ligament, and the accessory atlantoaxial ligament [13].

As illustrated by our case, good knowledge of the variations of the craniocervical junction can better help in interpreting imaging in trauma patients [14-20].

\section{Conclusions}

Interpreting post-traumatic imaging necessitates a good working knowledge of the more common anatomical variations in the region of the body being imaged. AO assimilation should be assessed when viewing imaging of the neck and craniocervical junction.

\section{Additional Information}

\section{Disclosures}

Human subjects: Consent was obtained by all participants in this study. Swedish Research Center, Institutional Review Office issued approval N/A. The institution does not require IRB approval for case reports or small case series. Conflicts of interest: In compliance with the ICMJE uniform disclosure form, all authors declare the following: Payment/services info: All authors have declared that no financial support was received from any organization for the submitted work. Financial relationships: All authors have declared that they have no financial relationships at present or within the previous three years with any organizations that might have an interest in the submitted work. Other relationships: All authors have declared that there are no other relationships or activities that could appear to have influenced the submitted work.

\section{References}

1. Electricwala AJ, Harsule A, Chavan V, Electricwala JT: Complete atlantooccipital assimilation with basilar invagination and atlantoaxial subluxation treated non-surgically: a case report. Cureus. 2018, 9:1327. 10.7759 /cureus.1327

2. Standring S: Gray's Anatomy: The Anatomical Basis of Clinical Practice. Elsevier, Philadelphia; 2016.

3. Yoganandan N, Pintar F, Baisden J, Gennarelli T, Maiman D: Injury biomechanics of C2 dens fractures . Ann Proceed Assoc Adv Automot Med. 2004, 48:323-337.

4. Yang SY, Boniello AJ, Poorman CE, Chang AL, Wang S, Passias PG: A review of the diagnosis and treatment of atlantoaxial dislocations. Global Spine J. 2014, 4:197-210. 10.1055/s-0034-1376371

5. Iwata A, Murata M, Nukina N, Kanazawa I: Foramen magnum syndrome caused by atlanto-occipital assimilation. J Neurol Sci. 1998, 154:229-231.

6. Sharma DK, Sharma D, Sharma V: Atlantooccipital fusion: prevalence and its developmental and clinical correlation. J Clin Diagn Res. 2017, 11:01-03. 10.7860/JCDR/2017/26183.9999

7. Kulkarni JV, Kulkarni R: Atlanto-occipital fusion - report of two cases . J Anat Soc India. 2003, 52:71-73.

8. Smith JS, Shaffrey CI, Abel MF, Menezes AH: Basilar invagination. Neurosurgery. 2010, 66:39-47.

9. Vakili ST, Aguilar JC, Muller J: Sudden unexpected death associated with atlanto-occipital fusion . Am J Forensic Med Pathol. 1985, 6:39-43.

10. Kimura Y, Seichi A, Gomi A, Kojima M, Inoue H, Kimura A: Acquired Chiari malformation secondary to atlantoaxial vertical subluxation in a patient with rheumatoid arthritis combined with atlanto-occipital assimilation. Neurol Med Chir. 2012, 52:683-686.

11. Tubbs RS, Chern JJ, Muhleman M, Loukas M, Shoja MM, Oakes WJ: Lateral compression of the foramen magnum with the Chiari I malformation: case illustrations. Child's Nerv Syst. 2013, 29:495-8.

12. Tubbs RS, Lancaster JR, Mortazavi MM, Shoja MM, Chern JJ, Loukas M, Cohen-Gadol AA: Morphometry of the outlet of the foramen magnum in crania with atlantooccipital fusion. J Neurosurg Spine. 2011, 15:55-59.

13. Tubbs RS, Salter EG, Oakes WJ: The accessory atlantoaxial ligament . Neurosurg. 2004, 55:400-404.

14. Shoja MM, Ramdhan R, Jensen CJ, Chern JJ, Oakes WJ, Tubbs RS: Embryology of the craniocervical junction and posterior cranial fossa, part I: development of the upper vertebrae and skull. Clin Anat. 2018, 31:466487. 10.1002/ca.23049

15. Shoja MM, Ramdhan R, Jensen CJ, Chern JJ, Oakes WJ, Tubbs RS: Embryology of the craniocervical junction and posterior cranial fossa, part II: embryogenesis of the hindbrain. Clin Anat. 2018, 31:488-500. 


\section{Cureus}

10.1002/ca.23048

16. Shoja MM, Johal J, Oakes WJ, Tubbs RS: Embryology and pathophysiology of the Chiari I and II malformations: a comprehensive review. Clin Anat. 2018, 31:202-215. 10.1002/ca.22939

17. Yoon SY, Moon HI, Lee SC, Eun NL, Kim YW: Association between cervical lordotic curvature and cervical muscle cross-sectional area in patients with loss of cervical lordosis. Clin Anat. 2018, 31:710-715.

10.1002/ca.23074

18. Badshah M, Soames R, Ibrahim M, Khan MJ, Khan A: Surface anatomy of major anatomical landmarks of the neck in an adult population. Clin Anat. 2017, 30:781-787. 10.1002/ca.22907

19. Sanchis-Gimeno JA, Perez-Bermejo M, Rios L, Llido S, Bastir M, Blanco-Perez E, Mata-Escolano F: Analysis of the relationship between the double transverse foramen and the possibility of developing clinical symptoms after whiplash. Clin Anat. 2017, 30:761-766. 10.1002/ca.22897

20. Shen XH, Xue HD, Chen Y, Wang M, Mirjalili SA, Zhang ZH, Ma C: A reassessment of cervical surface anatomy via CT scan in an adult population. Clin Anat. 2017, 30:330-335. 10.1002/ca.22847 